\title{
A Rare Case of Hepatitis E Causing Chronic Liver Disease
}

\author{
Dr. Aravind $\mathbf{S}^{1}$, Dr. Sulthan Raslin Salih ${ }^{2}$, Dr. Muhammed Shareef Thenath ${ }^{3}$, Dr. Rakesh T. R. ${ }^{4}$, \\ Th Bhimo Singh ${ }^{5}$ \\ ${ }^{1,2,3,4,5}$ Regional Institute of Medical Sciences, Imphal, Manipur, India,795004
}

\begin{abstract}
Introduction: Hepatitis $E$ is a form of viral hepatitis caused by Hepatitis $E$ virus. Hepatitis $E$ virus (HEV) is a singlestranded RNA virus in the Hepeviridae family with five genotypes. Until recently hepatitis $E$ was considered as an acute self-limiting disease. Reports of chronic HEV infection have been limited to immunosuppressed patients who are human immunodeficiency virus (HIV)-positive, have hematological malignancies, or are solid-organ transplant recipients. Case Report: We report a case of hepatitis $E$ causing chronic liver disease in a 25 year old immunocompetent male. Disease presented with fever and jaundice with a travel history to endemic region. Conclusion: This case highlights the importance of suspecting chronic HEV infection in patients with unexplained chronic hepatitis and liver cirrhosis even in an immunocompetent patient.
\end{abstract}

Keywords: Hepatitis E, CLD, HEV RNA, IgG Anti HEV, Jaundice

\section{Introduction}

Hepatitis $\mathrm{E}$ is a form of viral hepatitis caused by Hepatitis $\mathrm{E}$ virus. Hepatitis E virus (HEV) is a single-stranded RNA virus in the Hepeviridae family with five genotypes. Genotypes 1 and 2 are restricted to humans with genotype 1 predominant in Asia and genotype 2 in Africa and Mexico. HEV genotypes 3 and 4 infect humans as well as other mammalian species in a worldwide distribution. Genotype 5 is of avian origin and has only been described in birds [1].Most reported outbreaks have been related to consumption of fecally contaminated drinking water, as supported by the results of epidemiologic investigations and demonstration of HEV RNA in waste water, sewage, and drinking water. The outbreaks frequently follow heavy rains and floods, but some are related to decreased flow in rivers during hot summers, with a consequent increase in the risk of water contamination [2].

The illness begins insidiously with a prodromal phase with varying combinations of flu-like symptoms, fever, chills, abdominal pain, anorexia, aversion to smoking, vomiting, clay-colored stools, dark urine, diarrhea, arthralgias, and a transient macular skin rash. These prodromal symptoms are replaced in 1 to 7 days with jaundice, dark urine, light stool color, and itching, which last up to a few weeks. Physical examination reveals jaundice, a mildly enlarged, soft, and slightly tender liver, and at times splenomegaly. Laboratory test abnormalities include bilirubinuria, conjugated hyperbilirubinemia, and marked elevations in serum levels of ALT, AST, and GGTP. Serum ALT elevations may precede symptoms, and the magnitude of the elevation does not correlate with the severity of liver injury. Mild leukopenia and relative lymphocytosis may occur. Ultra-sonogram may show a mildly enlarged liver, increase in hepatic parenchymal echogenicity, gallbladder wall edema, prominence of portal venules, and a slightly enlarged spleen [3].

Until recently hepatitis E was considered as an acute selflimiting disease. Reports of chronic HEV infection have been limited to immune suppressed patients who are human immune deficiency virus (HIV)-positive, have hematologicalmalignancies, or are solid-organ transplant recipients, and receiving immunosuppressive drugs [4].Reduction of immune suppression and/or monotherapy with pegylated interferon or ribavirin has shown efficacy in the treatment of

Chronic HEV infection. A study in France of six kidney transplant recipients with chronic HEV genotype 3 infection demonstratedthatribavirin therapy for 3 months led to sustained virological response in four patients [5]. Here we describe a unique case of chronic hepatitis E, anti-HEV IgGpositive, anti-HEV IgM-negative, HEV RNA-positive in an immunocompetent patient which lead to chronic liver disease and cirrhosis.

\section{Case Report}

A 25 year old male residing in Imphal, Manipur, India came to Regional institute of medical sciences gastroenterology opd in august 2013 with history of jaundice and fever of 1 week duration. He is a post graduate student in arts and has a history of travel to Delhi 2 weeks before. He is a nonalcoholic and vegetarian. He did not give any history of surgery and blood transfusion. He has no significant history of illness in the past and no history of any drug intake. On examination he had icterus and mild hepatomegaly. His liver function was deranged with bilirubin of 7 and liver enzymes AST and ALT more than 1000. He was negative for dengue, malaria and typhoid antibodies. He was negative for hepatitis $\mathrm{A}, \mathrm{B}$ and $\mathrm{C}$ but was IgM hepatitis $\mathrm{E}$ positive. He was $\mathrm{IgG}$ negative for hepatitis E. HEV RNA was detected in serum with a titer of $2.3 * 10^{4} \mathrm{IU} / \mathrm{L}$. His ANA, serum ceruloplasmin and alpha 1 antytrypsin were normal. He was treated with oral Ursodeoxycholic acid and was advised good oral fluid intake. After 4 days his fever subsided and icterus decreased and his liver enzymes AST and ALT were 310 and 340 respectively. He was symptomatically better and was discharged. He again presented after 6 months in March2014 with icterus in gastroenterology opd. This time his serum bilirubin was 4 and AST and ALT were 440 and 470 respectively. The blood sample tested anti-HEV-IgG-positive

\section{Volume 4 Issue 11, November 2015}




\section{International Journal of Science and Research (IJSR) \\ ISSN (Online): 2319-7064 \\ Index Copernicus Value (2013): 6.14 | Impact Factor (2014): 5.611}

and anti-HEV IgM-negative. HEV RNA was detected in serum with a titer of $3.4 * 10^{4} \mathrm{IU} / \mathrm{L}$. Sequencing studies determined HEV genotype 3. His other viral marker including HIV, ANA, serum ceruloplasmin and alpha1 antitrypsin were negative. His serum iron profile was normal. Ultrasound abdomen showed liver parenchymal disease with mild ascites. His fibro scan showed liver cirrhosis. He was started on Ribavirin and peg interferon alpha $2 \mathrm{a}$ and discharged and followed up in gastroenterology opd. He got better and was negative for HepE RNA after 6 months.

\section{Discussion}

In this case report, our patient is a man from North East India with chronic HEV infection. In developing countries, HEV is generally perceived as an acute self-limiting disease, and travel to endemic regions is considered the primary risk factor. Phylogenetic analyses have shown that HEV genotype 1 is responsible for the majority of cases in developing countries, whereas the prevalent HEV genotype in Europe and North America is genotype 3 [6].

Our patient attended the gastroenterologyopd with jaundice and fever. During a diagnostic workup, HEV was identified as the underlying disease. The diagnosis was based on three factors: first, a moderate fluctuating transaminitis with an ALT ranging from 61 to $1100 \mathrm{U} / \mathrm{L}$, a typical pattern in chronic HEV infection [7]; second, the detection of specific HEV antibodies by enzyme-linked immunosorbent assay and immunoblot; and, third, the direct detection of virus-specific RNA by reverse transcription-quantitative polymerase chain reaction. Virus genotyping were performed by sequencing and revealed HEV genotype 3. HEV RNA was detectable in two serum samples taken over a period of 7 months. Thus, our patient tested positive for HEV RNA for more than 6 months, and this fits the definition of chronic HEV infection. In the course of an acute HEV infection, the highest level of viral nucleic acid in the blood is present before the occurrence of the first clinical symptoms and then rapidly declines in immunocompetent patients. After the onset of clinical symptoms, HEV RNA is usually detectable by polymerase chain reaction for only 14 to 28 days from blood, plasma, or serum. HEV genotype 3 has been reported for non-travel-associated infections in industrialized countries. Interestingly, a sequence database search revealed several closely related HEV sequences derived from swine as well as from humans in different parts of the world. In light of these findings and a recent report on the detection of $\mathrm{HEV}$ in porcine livers sold as food in southeastern Germany [8], our patient was questioned about his alimentary habits. However, ingestion of raw meat and contact with animals (including pigs) were denied. Thus, the source of infection and mode of transmission remain unclear. Several reports in the literature suggest that patients under immune suppression are at increased risk of acquiring autochthonous HEV infection with prolonged viral replication and potentially severe clinical consequences. In our case patient was immune competent and this was found very rare in literature.

Notably, severe complications have also been observed in patients with HEV infection after liver transplantation. In a recently published case, undetected HEV infection in a liver transplant donor actually caused chronic HEV and cirrhosis in the recipient [9]. In addition to acute and chronic HEV infections in patients with hematological malignancies [10], patients with HIV have been reported with chronic HEV. In our patient, antiviral treatment was initiated with ribavirin and peg interferon alpha $2 \mathrm{a}$ and patient become negative for HepE virus RNA after 6 months

\section{Conclusion}

Recent studies in solid organ transplant recipients have shown that acute HEV genotype 3 infection or reactivation in anti-HEV IgG-positive transplant recipients can lead to chronic hepatitis with progression to cirrhosis. Our patient also had HEV genotype 3infection but was immune competent. This case highlights the importance of suspecting chronic HEV infection in patients with unexplained chronic hepatitis and liver cirrhosis even in immunocompetent patients. This also points us towards the importance of taking hepatitis $\mathrm{E}$ vaccination especially for people travelling to endemic regions.

\section{References}

[1] Kamar N, Rostaing L, Abravanel F, Garrouste C, Lhomme $\mathrm{S}$, EspositoL, et al. Ribavirin therapy inhibits viral replication on patients withchronic hepatitis E virus infection. Gastroenterology 2010; 139:1612-1618.

[2] Drobeniuc J, Greene-Montfort T, Le NT, Mixson-Hayden TR,Ganova-Raeva L, Dong C, et al. Laboratory-based surveillance for hepatitisE virus infection, U.S. 2005-2012. Emerg Infect Dis 2013; 19:218-222.

[3] Abravanel F, Chapuy-Regaud S, Lhomme S, Dubois M, Peron JM,Alric L, et al. Performance of two commercial assays for detecting hepatitisE virus RNA in acute or chronic infections. J ClinMicrobiol2013;51:1913.

[4] Zhu FC, Zhang J, Zhang XF, Zhou C, Wang ZZ, Huang SJ, et al.Efficacy and safety of a recombinant hepatitis E vaccine in healthyadults: a large-scale, randomized, doubleblind, placebo-controlled phase III trial. Lancet 2010;376:895-902

[5] Kamar N, Rostaing L, Abravanel F,Garrouste C, Lhomme $\mathrm{S}$, EspositL, et al. Ribavirin therapy inhibits viral replication on patients withchronic hepatitis E virus infection. Gastroenterology2010; 139:1612-1618.

[6] Wedemeyer H, Pischke S, Manns MB. Pathogenesis and treatment of hepatitis E virus infection. Gastroenterology 2012;142:1388-1397

[7] Abravanel F, Chapuy-Regaud S, Lhomme S, Dubois M, Peron JM,Alric L, et al. Performance of two commercial assays for detecting hepatitisE virus RNA in acute or chronic infections. J ClinMicrobiol2013;51:1913.

[8] Zhu FC, Zhang J, Zhang XF, Zhou C, Wang ZZ, Huang SJ, et al.Efficacy and safety of a recombinant hepatitis E vaccine in healthyadults: a large-scale, randomized, doubleblind, placebo-controlled phase III trial Lancet2010;376:895-902

[9] Wenzel JJ, Preiss J, Schemmerer M, Huber P, Plentz A, Jilg W: Detection of hepatitis E virus (HEV) from porcine livers in Southeastern Germany and high sequence homology to human HEV isolates.J ClinVirol 2011, 52:5054.

[10] Kamar N, Bendall R, Legrand-Abravanel F, Xia NS, Ijaz S, Izopet J, Dalton HR: Hepatitis E.Lancet 2012, 379:24772488.

\section{Volume 4 Issue 11, November 2015}

